\title{
DESIGNING IN COMPLEXITY: HOW SOLUTION CONJECTURES INFORM PROBLEM EXPLORATION
}

\author{
Zhang, Wenlin; \\ Ma, Jin \\ Tongji University
}

\begin{abstract}
Engineering designers seek to explore 'real' problems that must be solved across design processes. This exploration might be challenging in complex problem situations. An effective way of encouraging design exploration is conjecture-based problem exploration-informing problem reinterpretation by potential solutions. However, little evidence indicated how this process unfolds, especially in complex problem situations. This study addresses this question by articulating the underlying cognitive mechanism of conjecture-based problem exploration. Situated in a creative design practice that tackles real-world, complex problem situations, we employ grounded theory to conduct qualitative coding of interview transcripts and documents elicited from ten multidisciplinary graduate students. We developed a three-phase process model to explain conjecture-based problem exploration: (1) triggering through analogizing, inspiring, evaluating, and questioning; (2) transitioning to problem space expansion; and (3) resulting in problem focus adjustment incrementally or radically. Our explanation contributes to design theory building and encourages engineering designers to embrace a dynamic view of design problems when addressing complexity.
\end{abstract}

Keywords: Design process, Design cognition, Co-evolution, Complexity, Conjecture-based problem exploration

\author{
Contact: \\ Zhang, Wenlin \\ Tongji University \\ College of Design and Innovation \\ China, People's Republic of \\ wenlindesign@hotmail.com
}

Cite this article: Zhang, W., Ma, J. (2021) 'Designing in Complexity: How Solution Conjectures Inform Problem Exploration', in Proceedings of the International Conference on Engineering Design (ICED21), Gothenburg, Sweden, 16-20 August 2021. DOI:10.1017/pds.2021.115 


\section{INTRODUCTION}

Formulating 'real' problems that require solving is an essential capacity of expert engineering designers (e.g., Atman et al., 2007). As design problems are ill-defined (Simon, 1973), designers have to engage in exploratory processes to deepen their understanding of problems (e.g., Cross, 2007). A variety of tactics have been identified to support these processes of problem exploration (e.g., Daly et al., 2018) in engineering design (e.g., Daly et al., 2018, Studer et al., 2018).

However, problem exploration might be challenging when designers confront increasingly complex problems. Complex problems may be not simply ill-defined, but also open, dynamic, usually located at the intersection of the social, economic, and environmental (van der Bijl-Brouwer, 2019). Designers need to repeatedly experiment with incremental steps to advance problem understanding and resolution (Norman and Stappers, 2015). Thus, the 'real' problems to be tackled can hardly be formulated without proposing conjectures when designing in complexity.

Co-evolution (Dorst, 2019) - a model for describing problem and solution exploration as mutually adaptive endeavours (Maher and Poon, 1996) - provides keys to addressing these complexities. According to co-evolution, a potential solution can be resulted from problem exploration (i.e., problem to solution transition), and the design problem can be re-interpreted in the light of an exploration of possible solutions (i.e., solution to problem transition) (Dorst and Cross, 2001). Prescriptive engineering design models, which emphasise that problem definition precedes solution exploration, aid this transition (Cross, 1993). However, how solution conjectures inform problem re-interpretation, which this study terms 'conjecture-based problem exploration', has drawn little attention to date.

Supporting conjecture-based problem exploration may improve design performance, especially in complex problem situations. Empirical evidence demonstrates that experienced designers frequently adopt conjecture-based problem exploration (Cross, 2004, Lawson, 1979, Lloyd and Scott, 1994), which also has a bearing on creativity cognition in design outcomes (e.g., Jin and Chusilp, 2006, Kruger and Cross, 2006, Lu, 2015). However, little effort is devoted to revealing how such cognitive mechanisms function, which is why Dorst (2019) calls for better articulation of how solution conjectures may inform problem exploration, especially within complex problem situations.

This study is a part of an ongoing inquiry to develop a theoretical explanation of the cognitive mechanisms behind conjecture-based problem exploration. Situated in a creative design practice tackling real-world, complex problem situations, we aim to answer the following research question: How do designers with multidisciplinary backgrounds use solution conjectures to inform problem exploration in complex problem situations? Our findings have implications for uncovering the underlying mechanisms of solution-focused design cognition (Kruger and Cross, 2006) and for supporting a comprehensive understanding of design co-evolution (Dorst, 2019).

The paper is structured as follows. In Section 2, we characterise design exploration in complex problem situations; review existing terms describing how solution conjectures inform problem exploration; and formalise the notion of 'conjecture-based problem exploration', illustrating its significance to design in complexity. Section 3 describes the research setting, methods, and qualitative coding process. Section 4 illustrates a model that explains the cognitive mechanisms behind conjecture-based problem exploration. In Section 5 and 6, we discuss our contributions to design theory building (Cash, 2018), the limitations of our study, and avenues for future research.

\section{THEORETICAL BACKGROUND}

\subsection{Design exploration in complex problem situations}

Design problems are ill-defined (Simon, 1973) with unclear parameters that require pinpointing problems before they can be solved. As Cross (2007, p. 78) puts it, "it is often not at all clear what "the problem" is, it may have been only loosely defined by the client, many constraints and criteria may be un-defined'. Problem formulation is thus a crucial component of engineering design processes (e.g., Atman et al., 2007), which require exploratory processes to formulate the 'real' problems that require solving.

Although there are tactics to support this exploration (e.g., Daly et al., 2018, Studer et al., 2018), working in fields beyond design to tackle increasingly complex problem situations creates special challenges (Dorst, 2015). In such situations, the problems are open, complex, usually located at the intersection of the economic, societal, and environmental (van der Bijl-Brouwer, 2019). Design practices also involve 
ongoing participatory processes in which designers and stakeholders from multidisciplinary backgrounds collaborate (Norman and Stappers, 2015, Sanders and Stappers, 2008). Designing in complexity involves explorations somewhat different from traditional engineering design practices.

Multiple perspectives inform the characterization of design exploration in complex problem situations. In organisational innovation, Snowden and Boone (2007) refer to incrementalism (i.e., advancing via incremental steps) (Lindblom, 1959) to advocate 'probe first, then sense, and then respond' in large, complex systems. Design researchers echo this perspective. Norman and Stappers (2015) suggest that the emergence of complex socio-technical problems does not stem from attempts to address initial issues, but rather arise during implementation. They propose a 'muddling through' pathway to resolve complex socio-technical problems, encouraging designers to experiment with small, incremental steps repeatedly to advance problem understanding and resolution. Simply put, problem exploration tactics derived from traditional engineering design practices may not work as expected when designing in complexity. Formulating the 'real' problem in complex problem situations may involve constant evolution, tightly linked to proposing and implementing solution conjectures.

\subsection{Conjecture-based problem exploration}

Co-evolution is one of the well-adapted notions to describe design exploration in complex problem situations (Dorst, 2019, van der Bijl-Brouwer, 2019). It conceptualises the design process as two notional spaces ('problem space' and 'solution space') interacting with each other until both are firmly defined (Maher and Poon, 1996). Problem space constitutes from problem entities like requirements, constraints, and needs, while solution space consists of solution entities like conjectures, concepts, and working principles (Martinec et al., 2020). According to co-evolution, a potential solution can be resulted from interpreting the problem, labelled as problem space to solution space transition. In parallel, problem re-interpretation can also be enacted in the light of an exploration of potential solutions, labelled as solution space to problem space transition (Dorst and Cross, 2001).

Aspects of problem space to solution space transition can be well captured by existing design models. These models emerge primarily from prescriptive engineering design literature grounded in design as a problem-solving activity, emphasising problem definition before solution exploration (Cross, 1993). Less explored is how solution conjectures inform problem re-interpretation, which Dorst (2019) addresses, by examining co-evolution in the briefing process, within and across design projects, to propose a better understanding of solution space to problem space transitions.

We scrutinize aspects of this transition in detail (Table 1). Darke (1979) is one of the pioneers in formalising this process, finds that renowned architects do not necessary list all constraints at the outset of a project. Instead, they fix on a particular objective or small groups of objectives, called 'primary generators', that give rise to proposed solutions. These objectives form 'a way in to the problem' that allows architects to understand it by trying solutions and seeing where it goes wrong. Subsequent researchers observing similar processes formalized them as solution-focused strategy (Lawson, 1979), solution-driven design (Kruger and Cross, 2006), problem redefinition loop (Jin and Chuslip, 2006), and solution mapping (Lee et al., 2020). For the sake of clarity, we call this cognitive process 'conjecture-based problem exploration'. The conceptualisation aims to outline the key features of this cognitive process indicated by existing evidence with a minimum set of descriptors. We delimit its definition as the designer propose speculative solutions serving as conjectures to adjust or reformulate their current understanding of the problem situation.

Table 1. Conceptualisations relevant to conjecture-based problem exploration

\begin{tabular}{|l|c|r|}
\hline Terminology & Author(s) & Definition \\
\hline Primary generator & Darke, 1979 & $\begin{array}{r}\text { A particular objective or small groups of objectives that } \\
\text { give rise to a proposed solution or conjecture }\end{array}$ \\
\hline $\begin{array}{l}\text { Solution-focused } \\
\text { ttrategy }\end{array}$ & Lawson, 1979 & $\begin{array}{r}\text { Focus on generating a solution and testing its feasibility } \\
\text { in order to improve the understanding of the problem }\end{array}$ \\
\hline Solution mapping & Lee et al., 2020 & $\begin{array}{l}\text { A specific solution-first design process beginning with a } \\
\text { novel technological solution and searching for a specific } \\
\text { application problem }\end{array}$ \\
\hline $\begin{array}{l}\text { The transition from } \\
\text { solution space to } \\
\text { problem space }\end{array}$ & $\begin{array}{l}\text { Dorst and Cross, } \\
\text { 2001, Maher and } \\
\text { Poon, 1996 }\end{array}$ & $\begin{array}{r}\text { Identifies a partial structure in the solution space and } \\
\text { then uses that to structure the problem space }\end{array}$ \\
\hline
\end{tabular}




\begin{tabular}{|l|c|r|}
\hline $\begin{array}{l}\text { Solution-driven } \\
\text { design }\end{array}$ & $\begin{array}{c}\text { Kruger and Cross, } \\
2006\end{array}$ & $\begin{array}{r}\text { Focus on generating solutions and only gathers } \\
\text { information that is needed to further develop a solution }\end{array}$ \\
\hline $\begin{array}{l}\text { Problem redefinition } \\
\text { loop }\end{array}$ & $\begin{array}{c}\text { Jin and Chuslip, } \\
2006\end{array}$ & $\begin{array}{r}\text { Examining the concept against problem requirements and } \\
\text { constraints leads the designer to re-think, revise, or } \\
\text { elaborate on the original problem definition }\end{array}$ \\
\hline
\end{tabular}

\section{RESEARCH SETTING AND METHODS}

Our empirical study occurred in a six-week studio for design graduate students. The design brief was to enhance community coherence by redesigning a security room's surroundings in the context of COVID-19. The studio was selected for three reasons: (1) The design practice encountered a complex problem situation. To protect neighbours from infection, the security room design needed to ensure physical social distancing, while maintaining emotional community coherence. This situation was complex under pandemic and political regulations, which are both emergent and uncertain. Attaining this goal also involved constant negotiation between multiple stakeholders, such as security guards, neighbours, property administrators, and community committee members. (2) Students observably interpreted the problem situation creatively. As creative design involves more frequent problem redefinitions than routine design (Jin and Chusilp, 2006), eliciting data from this studio allowed us to capture a robust number of conjecture-based problem explorations. (3) We observed students with different backgrounds (architecture design, landscape architecture, industrial design, interaction design, and environmental design) interpreting problem from different perspectives, proposing solutions including community services, public products, interactive devices, and architectural modifications. This diversity provided difference-maximising material (i.e., multifaceted variations of conjecture-based problem exploration), while generating models (Glaser and Strauss, 1967, p. 56), which is crucial to generalisability and theoretical relevance (Eisenhardt and Graebner, 2007).

We selected grounded theory (Corbin and Strauss, 2014) as our methodology for its fitness for theorizing a phenomenon that has drawn little theoretical explanation (i.e., conjecture-based problem exploration). We adopted the semi-structured interview method as it offered us the chance to probe deeper into specific narratives undergirding the cognitive process of conjecture-based problem exploration. We recruited ten participants (two males and eight females, sequenced as P1-P10 according to the date of interview), obtaining informed consent to record interviews and access design externalisations. Interview duration ranged from 40-80 minutes. The protocol focused on how the interviewee's problem and solution focus evolved and how they incubated, elaborated, and iterated design frames. We prompted narratives while interviewing to detail how problem-solution transitions informed interviewees' problem understandings and subsequent solution attempts. Periodic presentation files, sketches, and design documents conveyed designers' evolving rationales, serving as elicitation materials to retrieve memories of certain cognitive episodes during interviews (Crilly, Blackwell and Clarkson, 2006). The varied data collection methods supported the reconstruction of a continuous narrative of participants' cognitive processes.

When conducting theoretical sampling, data collection and analysis evolved in parallel to inform each other's development (Corbin and Strauss, 2014, p. 137). For instance, the analysis of and reflection upon previous data caused the first author to recruit two participants with architectural backgrounds, who offered solutions from unique perspectives. Constant comparative analysis went hand in hand with theoretical sampling. The comparison involved both constantly going back and forth between data and theory and iteratively reflecting on old and newly added materials (Corbin and Strauss, 2014, p. 93, Glaser and Strauss, 1967, p. 28-57). The sampling and analysis went until categorical saturation was reached.

We developed a variation on the three-step data analysis procedure (Corbin and Strauss 2014). We transcribed interview materials in full, combining video and pictorial documents to capture information necessary for understanding details conveyed verbally. The first author conducted all rounds of the analysis. For open coding, all problem-solution transition episodes were codified. For axial coding, we highlighted the transitioning episodes from solution to problem to focus on the subject under scrutiny. For selective coding, we grouped higher-level themes to explain how solution conjectures inform problem exploration. We also adapted visual mapping strategy to represent problem-solution transition, visualising each episode in detail to support theoretical abstraction (Langley, 1999). Figure 1 provides an example of the coding process. 


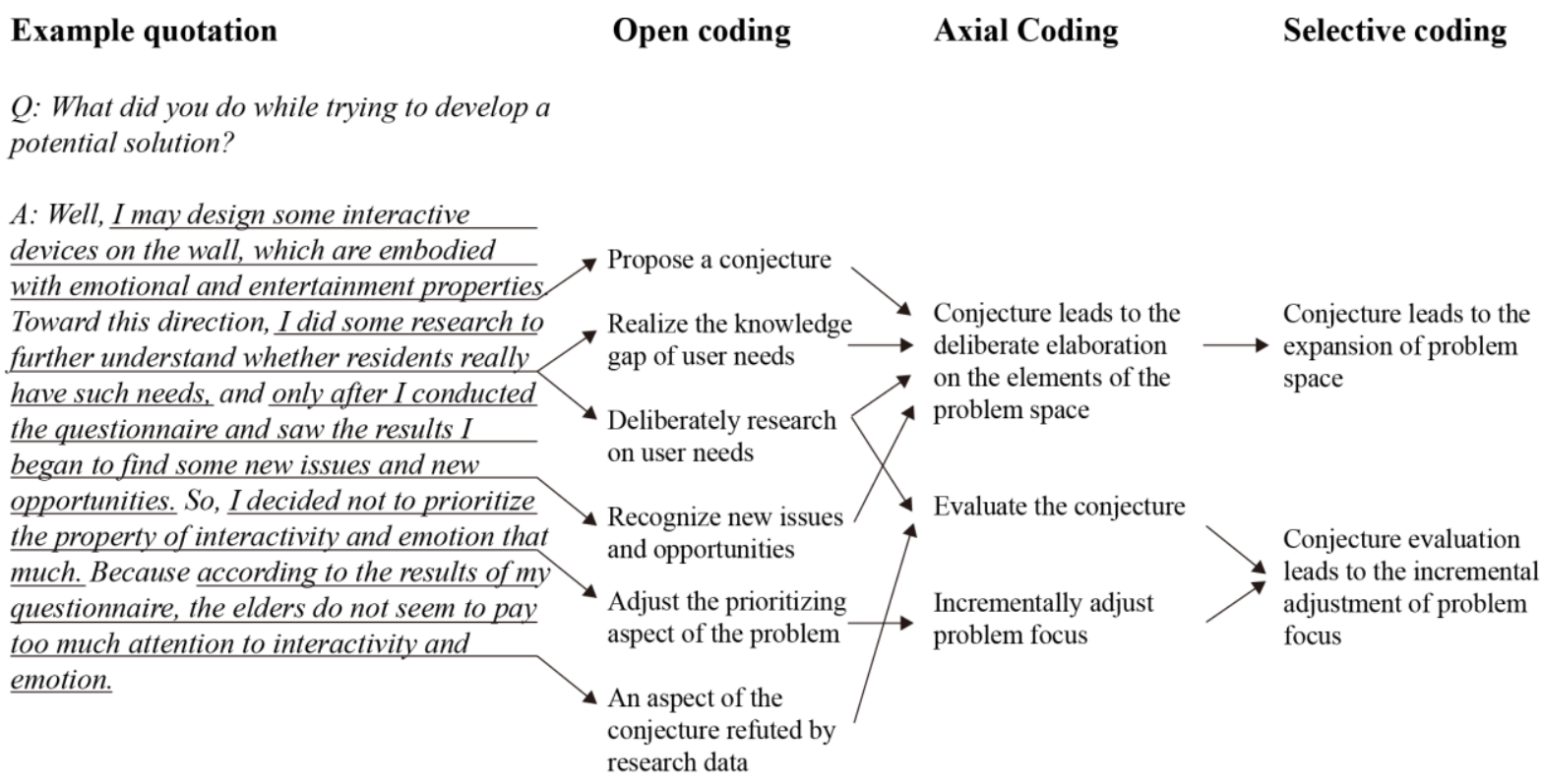

Figure 1. A segment of coding process

\section{RESULTS}

Analysis indicated that the cognitive process of conjecture-based problem exploration was pervasive throughout the design process. Figure 2 presents a process model of the cognitive mechanisms behind conjecture-based problem exploration. This model is chronologically sequenced as stages of triggering, antecedent, transient state, and outcome. Some of the primary building blocks are illustrated below:
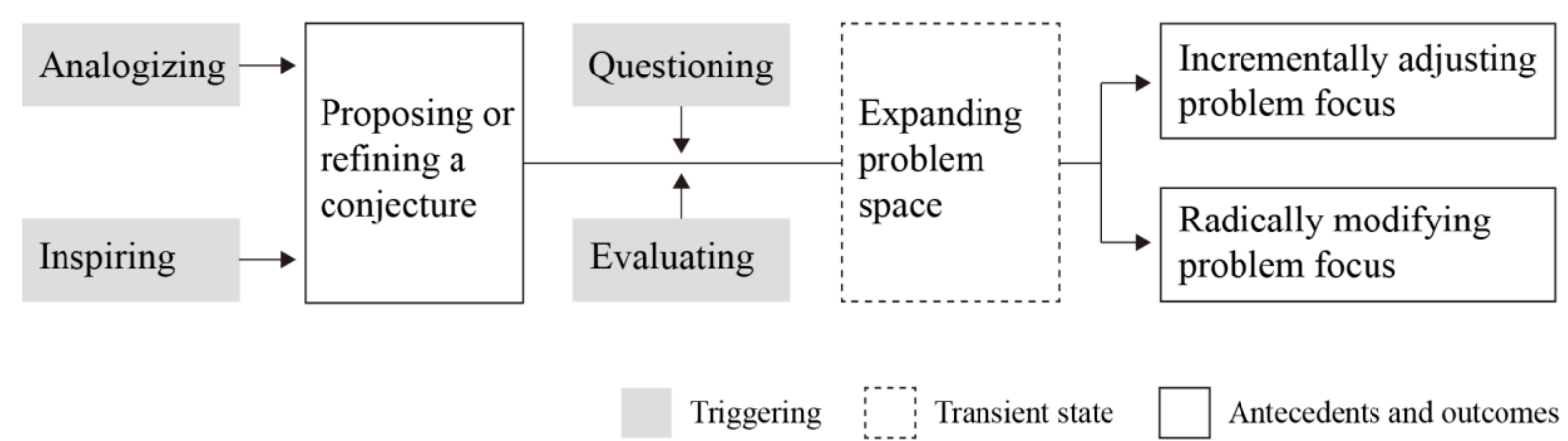

Figure 2. The cognitive mechanism behind conjecture-based problem exploration

\subsection{Triggering}

We discerned four tactics that triggered conjecture-based problem exploration: analogising, inspiring, evaluating, and questioning. The former two take place before conjecture proposition or refinement, while the latter two occur after a conjecture is proposed or refined. Each tactic can occur separately or simultaneously (e.g., designers may become inspired and then re-interpret the problem, or they may continue to evaluate a conjecture after being inspired, which influences problem exploration). We describe each tactic below.

\subsubsection{Analogizing}

As an effective tactic for supporting design creativity (e.g., Chan and Schunn, 2014), analogising involves accessing and transferring previously acquired knowledge of objects, attributes and relations in order to support current problem-solving and decision-making (e.g., Gentner, 1983). Analogising may trigger conjecture proposition and further alter a designer's original problem focus. For example, P3 attempted to 'make the security room communicate with neighbours through a similar form of the lighthouse.' She then altered her problem focus to 'how the shape, the brightness, and the flicker frequency of the light could enable this communication (P3).' Similarly, P4 noticed that the pandemic had exacerbated isolation of elders. She compared the elderly to a drifting ship, and the gatehouse to a port. She wanted to 'give [the security room] a sense of belonging and returning, [...] so they [the 
residents] can feel a sense of companionship without adding too much burden [to the security guard] (P4).' She altered her problem scope to 'how to create a sense of companionship for neighbours' and 'how to reduce the burden on security guards'.

\subsubsection{Inspiring}

Problem exploration can be triggered when the designer is getting inspired. This inspiration process can be enacted by stimuli, heuristics, and design principles. For instance, P5 noticed that 'many placemaking cases created visual modifications on the wall, [...] giving the space a richer sense of depth visually.' Inspired by visual stimuli, she recognised that 'empowering community vitality' was a problem to be tackled. She devoted efforts to explore this problem later on: 'It [the visual stimuli] suddenly reminded me that promoting community vitality was essential in the context of the pandemic, and the visual representation may afford this validity in a visual way (P5).'

P10 mentioned receiving inspiration from the heuristic - a context-dependent directive, based on intuition, tacit knowledge, or experiential understanding, which provides design process direction to increase the chance of reaching a satisfactory but not necessarily optimal solution (Fu, Yang and Wood, 2016). She described how the heuristic of 'enabling light encounters' inspired her to design in situations of weak social ties, and how the heuristic triggered her to scope the problem of 'how to support interactions between stakeholders': 'I read a paper discussing the notion of light encounter in community contexts. [...] [This notion] fits well with neighbour relations in the context of pandemic. [...] I created a questionnaire to better understand the social ties between security guards and neighbours. Where and how they interact with each other. [...] To think about how to enable social interactions between stakeholders to initiate community activities (P10).'

Adopting design principles - fundamental rules or laws derived inductively from extensive experience and/or empirical evidence to provide design process guidance to increase the chance of reaching a successful solution (Fu, Yang and Wood, 2016) — can inspire problem exploration. For instance, P2 proposed a tangible label on the notice board as 'the physical objects can convey information in a very intuitive and simple way.' She invited the design principle of 'intuition and simplicity' to guide her focus on the elders' functional demand.

\subsubsection{Evaluating}

In evaluating, a designer examines the solution conjecture against problem requirements and constraints by researching, modelling, or scenario simulating. P1 evaluated his solution conjecture by interviewing potential users. He noticed that 'during the epidemic, the security guards became much busier, and the neighbours' attitude towards them also changed'. Later, he focused on reducing the security guard's burden and spotlighted the problem of 'how to build a better relationship between them [the security guards and the residents] (P1)'. Likewise, P10 attempted to modify the notice board at the community entrance. She evaluated the feasibility through 'modelling in SketchUp [a modelling software], it was all about sketches and models, trying to do some small experiments (P10).' Through modelling, she recognised that 'modifying the notice board can only be justified when I make a separation between flows of people and cars, so it seems to be a problem of how to separate the flows of people and cars in such a narrow space (P10).' P2 described how she evaluated the solution conjecture through simulating the usage scenario: 'If you want to tell the elderly how to walk in the real context you just need to demonstrate on the map by moving the label.' While simulating this scenario, she recognised the relaxing demand of elders who 'can also take a break while looking for information on the board and sit around talking with each other (P2).'

\subsubsection{Questioning}

Instructors, partners, or stakeholders questioning the solution conjecture may induce cognitive processes of conjecture-based problem exploration. P7 stated that her initial problem focus was that the community entrance 'is not large enough for parking and organising activities.' P7 supposed to resolve this problem by 'adding a floor to the existing security room and expand the area on the upper floor (P7).' The instructor, mentioning the constraints of high construction costs and neighbours' potential opposition, questioned this conjecture. Considering these constraints, P7 adjusted her problem focus to cost, efficiency, and functionality: 'It is all about the cost and ease of construction. So, I came up with the basic module of a square, which is a more realistic form in terms of combination, cost, production.' 


\subsection{Expanding problem space}

The transient state between conjecture proposition and problem exploration is expansion of problem space - designers incorporate new problem entities (e.g., requirements, constraints, and needs) into the existing problem space. Problem space expansion can occur either unintentionally or deliberately. For instance, all participants expressed their preference to approach the situation in some particular ways at the outset of design. P6 commented that he usually conducts research on 'site characterization', 'spatial setting', and 'flow line'. When considering new solution conjectures, he constantly takes more problem entities into consideration, and some entities (e.g., 'interaction modalities' and 'user behaviour') largely deviated from his initial focus. P6 did not notice that he was considering more entities when proposing potential solutions, but when asked how his scoping evolved, he reflected that: 'I tended to research on spatial settings and [physical] configurations at the beginning, but you know the proposed concept need to be examined in as many aspects as possible. So only when a new solution emerges, I start to take other aspects such as elder needs and social interactions into consideration (P6).'

P8 described how conjectures informed problem space expansion: 'I wanted to make a place where people could rest, and thought of a park that has undulating terrain. Then I thought I could create undulating terrain [behind the security room], something like a little stage. The undulating step would suggest people to sit there, and with the semi-open space, some small-scale community activities could be initiated naturally. In particular, elders are the majority of this community, and they need to take breaks. Their grandchildren go back and forth between home and school, and they also need to take breaks or pause for a while.' P8 started by focusing on the requirement of 'neighbour rest' to propose 'building an undulating park place'. This conjecture enabled her to take more entities into account unintentionally, such as 'form language' (e.g., the undulating step as a metaphor for the act of sitting)', 'social activities', and 'user behaviour'.

In other cases, solution conjecture may inform designers to realise knowledge gaps, motivating them to explore a particular area of the problem space deliberately. P4 proposed a conjecture to realise that she lacks understanding of whether the neighbours have the requirement she hypothesised. She 'conducted field research to verify whether the concept is feasible or not (P4)' and found that 'at such an exceptional time [the pandemic], some salient issues emerged. For instance, the need to ensure safety, [...] and at the same time to maintain the emotional coherence between neighbours... (P4)' She thus added new issues of 'safety' and 'emotional coherence' to the existing problem space.

\subsection{Incrementally adjusting problem focus}

Bridging between conjectures and problems may inform the designer to adjust problem focus (i.e., the problem entities they pay close attention to) incrementally. P2 demonstrated how her problem focus shifted incrementally: 'Designing [an installation on the wall] for emotional interactions is one of my main design directions. [...] So [after conducting the research], I decided not to prioritise the property of interactivity and emotion that much. Because according to the results of my questionnaire, the elders do not seem to pay too much attention to interactivity and emotion. What they really need is an efficient way to convey information. So, after then, I was more convinced to design for conveying information.' P2 started by focusing on 'emotional interaction' and adopted 'an installation on the wall for emotional interactions' as her primary solution direction. Research revealed that elders are more interested in efficient ways to convey information, so she prioritised 'information and communication'.

She continued: 'I made a map and added a movable label on it to give directions to the elderly. Physical objects can convey information in a very intuitive and simple way. [...] It is no longer the original concept that is more of an entertaining property. The current concept is more [concerned] about the function (P2).' After a while, she added: 'I think they [the elders] might need some accessible seats. Because they can take a break while looking for information on the board and sit around to talk with each other (P2).' As is reported, she further developed the solution as 'a wayfinding installation', which led her to focus on the requirement of 'elderly rest'. She further refined the solution by adding the element of 'accessible seat'. As her problem focus moved from 'emotional interaction' to 'information and communication', she expanded her problem focus to cover 'user requirements'. 


\subsection{Radically modifying problem focus}

Proposing or refining a solution conjecture may yield a new problem focus immediately. Such radical shifts start from the proposition of a novel conjecture described as 'unexpected' or 'surprised' (P1-P4, P6, P8). Such conjectures induce designers to develop brand-new perspectives for problem interpretation and suddenly open novel pathways to solution development. For instance, P8 experienced the moment she got stuck to push her design forward. She was trying to 'add some interactive devices to the façade of the security room (P8)'. This concept was somewhat refuted by the constraint that prolonged stays around the security room could impede traffic. Despite efforts to develop lighter, faster interactive techniques, she was still unsatisfied with the solution.

This confusion was suddenly resolved when she came up with the idea of 'encircling public furniture' - the lightweight furniture made up of bamboo frames encircling around the community entrance. As she noted: 'The lightweight frame on the public furniture [...] can be built flexibly. [...] So, it [the interactive device] does not necessarily need to be installed on the façade of the security room. Rather, it can be adaptively placed in low-traffic locations according to specific community scenarios. [...] So, the neighbours don't have to stay for a long time to interact with it. They can take part in its [the public furniture's] growth indirectly by storing stuff temporarily, posting notices, etc. [...] The signboard on its [the public furniture] top also has a display function. So, it creates a place for community branding and feature display at the entrance of the community (P8).' The breakthrough occurred when she realised that she need not mount the interactive device on the façade of the security room. Instead, it could be installed in the encircling spaces flexibly surrounding the community entrance. The new solution changed her problem focus from 'prolonged stays around the security room may impede traffic' to new problem entities like 'product form', 'flexible configuration', and 'branding and display'. She further modified her solution direction as 'indirect participation', as it proved more reasonable than 'fast and light interaction' in the community entrance space.

\section{DIscussion}

Based on qualitative analysis of data elicited from the real-world design practices in a complex problem situation, this study formalises the notion of conjecture-based problem exploration and develops a process model to explain its underlying cognitive mechanism. Our findings contribute to uncovering the unfolding dynamics of solution-focused design processes. Ever since Darke (1979) and Lawson (1979) observed and formalised the solution-focused design process, increasing evidence reveals that solution-focused strategies are frequently adopted by experienced designers (Cross, 2004, Lawson, 1979, Lloyd and Scott, 1994) and are highly relevant to the creativity of design outcomes (e.g., Jin and Chusilp, 2006, Kruger and Cross, 2006, Lu, 2015). This study adds to this body of research by further uncovering the mechanisms behind solution-focused design processes. Lee et al. (2020) report similar findings in technological application settings, decerning cognitive strategies used in a specific solution-first design process called solution mapping - engineering designers begin with a novel technological solution and searches for a specific application problem. This study extends on this work to further uncover how a solution-first design process may unfold when designing in complex problem situations.

Our research contributes to advancing understandings of design co-evolution. Dorst (2019) suggests a better articulation of the transition from solution space to problem space, labelled as the 'upward jump'. We responded to this call by specifying this 'upward jump' in a specific design challenge to tackle a complex problem situation. We generalised a process model to illustrate the triggering, the transient state, and the outcomes of this cognitive process. Our findings can be positioned in an emerging strand of research that seeks a more comprehensive understanding of co-evolution transition episodes. Dankfort, Roos and Goncalves (2018) demonstrate that stimuli could support design teams framing shared understanding and, as such, have a positive impact on the co-evolution of the design process. Cash and Goncalves (2017) investigate information use and knowledge sharing activities across co-evolutionary transitions. Our findings echo these works, providing a detailed process view of how designers become inspired, how they propose or refine conjectures after then, and how conjectures ultimately induce problem re-interpretations. We further suggested analogising, evaluating, and questioning as potential tactics for triggering co-evolution transitions.

An interesting observation is that several participants of our study expressed embarrassment to acknowledge that they had proposed solutions before delving deeper into the problem. They also felt 
ashamed admitting that they went back to the problem while working on solutions. Similar observations were reported by Storm, van Maanen, and Goncalves $(2019$, p. 365), who noticed that 'students perceived the problem space to be completely fixed once they defined it, even if they discovered disparate information along the way.' This observation raises concerns that (novice) design practitioners may lack the awareness that they constantly reformulate problems by proposing solution conjectures and thus underestimate problem reformulation's potential benefit to design performance. The origin of this embarrassment may be the preference for a linear, nearly wellstructured design process in design courses and organisations, as P8 indicated. However, our analysis clarifies that conjecture-based problem exploration is pervasive across the design process. We encourage design practitioners to embrace a more dynamic view of design problems when designing incomplexity.

One should employ caution in generalising our present model to design practices beyond the empirical setting of our study. Our findings should be seen as a momentary product with several limitations, being written with the assumption that it is still developing rather than an established one (Glaser and Strauss, 1967, p. 32). First, designing in complex problem situations generally involves an ongoing collaborative and participatory process. Despite efforts to maximise difference by sampling multidisciplinary participants, this study does not account for the social aspects of conjecture-based problem exploration. Second, despite retrospective interview offered us a chance to elicit enriched rationales for specific cognitive episodes, we may also lose detail to represent the whole picture of designers' reasoning processes. Future research may contribute to model refinement by examining prolonged design projects longitudinally, which involves multiple stakeholders and designers with different levels of expertise.

\section{CONCLUSION}

In this study, we formalised the notion of 'conjecture-based problem exploration', clarified its relevance to design exploration in complex problem situations, and developed a process model to explain its cognitive mechanisms. Conducting qualitative research on ten multidisciplinary students approaching a real-world complex problem situation, we found that, when designing in complexity, conjecture-based problem exploration undergoes three sequential phases: triggering through analogising, inspiring, evaluating, and questioning; transitioning to problem space expansion; and resulting in problem focus adjustment either incrementally or radically. Our findings contribute to design theory building by uncovering the underlying mechanisms behind solution-focused design cognition and supporting a comprehensive understanding of design co-evolution. We encourage engineering designers to embrace a dynamic view of design problems when designing in complexity.

\section{REFERENCES}

Atman, C.J., Adams, R.S., Cardella, M.E., Turns, J., Mosborg, S. and Saleem, J. (2007), "Engineering design processes: A comparison of students and expert practitioners", Journal of Engineering Education, Vol. 96 No. 4, pp. 359-379. https://doi.org/10.1002/j.2168-9830.2007.tb00945.x

Bijl-Brouwer, M. van der. (2019), "Problem framing expertise in public and social innovation", She Ji: The Journal of Design, Economics, and Innovation, Vol. 5 No. 1, pp. 29-43. https://doi.org/10.1016/j.sheji.2019.01.003

Cash, P. (2018), "Developing theory-driven design research", Design Studies, Vol. 56, pp. 84-119. https://doi.org/10.1016/j.destud.2018.03.002

Cash, P. and Goncalves, M. (2017), "Information-triggered co-evolution: A combined process perspective", In: Christensen, B.T., Ball, L.J. and Halskov, K. (Ed.), Analysing design thinking: Studies of cross-cultural cocreation, CRC Press, Boca Raton, Florida, pp. 501-520. https://doi.org/10.1201/9781315208169-27

Chan, J. and Schunn, C. (2014), "The impact of analogies on creative concept generation: Lessons from an in vivo study in engineering design”, Cognitive Science, Vol. 39 No. 1, pp. 126-155. https://doi.org/10.1111/cogs.12127

Corbin, J.M. and Strauss, A.L. (2014), Basics of qualitative research: Techniques and procedures for developing grounded theory (4th Edition), Sage Publications, Thousand Oaks, CA.

Crilly, N., Blackwell, A. and Clarkson, P.J. (2006), "Graphic elicitation: Using research diagrams as interview stimuli." Qualitative Research, Vol. 6 No. 3, pp. 341-366. https://doi.org/10.1177/1468794106065007

Cross, N. (1993), “A history of design methodology”, In: DeVries, M.J., Cross, N. and Grant, D.P. (Ed.), Design Methodology and Relationships with Science, Springer Press, Dordrecht, The Netherlands.

Cross, N. (2007), Designerly ways of knowing, Springer, London, UK. 
Cross, N. (2004), "Expertise in design: An overview”, Design Studies, Vol. 25 No. 5, pp. 427-441. https://doi.org/10.1016/j.destud.2004.06.002

Daly, S.R., McKilligan, S., Studer, J.A., Murray, C.K. and Seifert, L.M. (2018), "Innovative solutions through innovated problems”, International Journal of Engineering Education, Vol. 34 No. 2(B), pp. 695-707.

Dankfort, Z.S., Roos, L. and Goncalves, M.G. (2018), "Inspiring co-evolution moves and creativity in design teams", The Fifth International Conference on Design Creativity, Bath, UK, January 31st-February 2nd, 2018, pp. 395-402.

Darke, J. (1979), “The primary generator and the design process”, Design Studies, Vol. 1 No. 1, pp. 36-44. https://doi.org/10.1016/0142-694X(79)90027-9

Dorst, K. (2019), “Co-evolution and emergence in design”, Design Studies, Vol. 65 No. C, pp. 60-77. https://doi.org/10.1016/s0954-1810(96)00047-7

Dorst, K. and Cross, N. (2001), "Creativity in the design process: Co-evolution of problem-solution", Design Studies, Vol. 22 No. 5, pp. 425-437. https://doi.org/10.1016/S0142-694X(01)00009-6

Dorst, K. (2015), Frame innovation: Create new thinking by design, MIT Press, Cambridge, MA.

Eisenhardt, K.M. and Graebner, M.E. (2007), "Theory building from cases: Opportunities and challenges", Academy of Management Journal, Vol. 50 No. 1, pp. 25-32. https://doi.org/ 10.2307/20159839

Fu, K.K., Yang, M.C. and Wood, K.L. (2016), "Design principles: Literature review, analysis, and future directions", Journal of Mechanical Design, Transactions of the ASME, Vol. 138 No. 10, pp. 1-13. https://doi.org/10.1115/1.4034105

Gentner, D. (1983), "Structure-mapping: A theoretical framework for analogy", Cognitive Science, Vol. 7 No. 2 , pp. 155-170. https://doi.org/10.1016/S0364-0213(83)80009-3

Glaser, B.G. and Strauss, A.L. (1967), Discovery of grounded theory: Strategies for qualitative research, The Sociology Press, Mill Valley, CA.

Jin, Y. and Chusilp, P. (2006), "Study of mental iteration in different design situations", Design Studies, Vol. 27 No. 1, pp. 25-55. https://doi.org/10.1016/j.destud.2005.06.003

Kruger, C. and Cross, N. (2006), "Solution driven versus problem driven design: Strategies and outcomes", Design Studies, Vol. 27 No. 5, pp. 527-548. https://doi.org/10.1016/j.destud.2006.01.001

Langley, A. (1999), "Strategies for theorizing from process data", Academy of Management Review, Vol. 24 No. 4, pp. 691-710. https://doi.org/10.5465/amr.1999.2553248

Lawson, B.R. (1979), “Cognitive strategies in architectural design”, Ergonomics, Vol. 22 No. 1, pp. 59-68. https://doi.org/10.1080/00140137908924589

Lee, J.W., Daly, S.R., Huang-saad, A., Rodriguez, G. and Seifert, C.M. (2020), “Cognitive strategies in solution mapping: How engineering designers identify problems for technological solutions", Design Studies, Vol. 71 No. C, pp. 1-33. https://doi.org/10.1016/j.destud.2020.100967

Lindblom, C.E. (1959), “The science of 'muddling through"”, Public Administration Review, Vol. 19 No. 2, pp. 79-88. https://doi.org/10.1016/B978-0-08-017066-4.50015-1

Lloyd, P. and Scott, P. (1994), "Discovering the design problem”, Design Studies, Vol. 15 No. 2, pp. $125-140$. https://doi.org/10.1016/0142-694X(94)90020-5

Lu, C.C. (2015), "The relationship between student design cognition types and creative design outcomes", Design Studies, Vol. 36 No. C, pp. 59-76. https://doi.org/10.1016/j.destud.2014.08.002

Maher, M. and Poon, J. (1996), "Modelling design exploration as co-evolution", Computer-Aided Civil and Infrastructure Engineering, Vol. 11 No. 3, pp. 195-209. https://doi.org/10.1111/j.1467-8667.1996.tb00323.x

Martinec, T., Škec, S., Perišíc, M.M. and Štorga, M. (2020), "Revisiting problem-solution co-evolution in the context of team conceptual design activity”, Applied Sciences (Switzerland), Vol. 10 No. 18. https://doi.org/10.3390/APP10186303

Norman, D.A. and Stappers, P.J. (2015), “DesignX: Complex socio-technical systems”, She Ji: The Journal of Design, Economics, and Innovation, Vol. 1 No. 2, pp. 83-106. https://doi.org/10.1016/j.sheji.2016.01.002

Sanders, E.B.-N. and Stappers, P.J. (2008), "Co-creation and the new landscapes of design”, CoDesign, Vol. 4 No. 1, pp. 5-18. https://doi.org/10.1080/15710880701875068

Simon, H.A. (1973), "The structure of ill structured problems", Artificial Intelligence, Vol. 4, pp. 181-201. https://doi.org/10.1016/0004-3702(73)90011-8

Snowden, D.J. and Boone, M.E. (2007), “A leader's framework for decision making”, Harvard Business Review Vol. 85 No. 11, pp. 68.

Storm, R., van Maanen, J. and Goncalves, M. (2019), "Reframing the design process: Integrating goals, methods and manifestation into the co-evolution model", Proceedings of the International Conference on Engineering Design, Delft, The Netherlands, August 5-8, 2018, Cambridge University Press, Cambridge, UK, pp. 359-368. https://doi.org/10.1017/dsi.2019.39

Studer, J.A., Daly, S.R., McKilligan, S. and Seifert, C.M. (2018), "Evidence of problem exploration in creative designs", Artificial Intelligence for Engineering Design, Analysis and Manufacturing, Vol. 32 No. 4, pp. 415-430. https://doi.org/10.1017/ S0890060418000124 